\title{
Mixed Synchronization of Chaotic Financial Systems by Using Linear Feedback Control
}

\author{
Ke Ding ${ }^{1,2,3}$ and Xing $\mathrm{Xu}^{4}$ \\ ${ }^{1}$ School of Information Technology, Jiangxi University of Finance and Economics, Nanchang 330013, China \\ ${ }^{2}$ Jiangxi E-Commerce High Level Engineering Technology Research Centre, Jiangxi University of Finance and Economics, \\ Nanchang 330013, China \\ ${ }^{3}$ Higher Education Division, Central Queensland University, Rockhampton, QLD 4702, Australia \\ ${ }^{4}$ School of Business Administration, Jiangxi University of Finance and Economics, Nanchang 330013, China \\ Correspondence should be addressed to Ke Ding; keding@jxufe.edu.cn
}

Received 15 June 2016; Revised 26 September 2016; Accepted 3 October 2016

Academic Editor: David Arroyo

Copyright (C) 2016 K. Ding and X. Xu. This is an open access article distributed under the Creative Commons Attribution License, which permits unrestricted use, distribution, and reproduction in any medium, provided the original work is properly cited.

This paper deals with the mixed synchronization (coexistence of synchronization and antisynchronization) of two chaotic financial systems. Two mixed synchronization criteria for two chaotic financial systems are derived with a single controller and without external controls, respectively. In addition, the control method and synchronization criteria are applied to study the mixed synchronization of a class of modified chaotic financial systems. Three examples are used to illustrate the effectiveness of our derived results.

\section{Introduction}

Many dynamical behaviors of fluctuations for investments, prices, and interest rates can be described by a three-dimensional financial system [1]. By choosing some proper parameters, the chaotic behaviors have been generated by financial systems. The chaos results in the unpredictable evolution during the stabilization for financial systems. In order to control chaotic financial systems, synchronization of two chaotic financial systems has been studied. The classical synchronization of two chaotic systems refers to the variables of one system which achieve the consensus with the counterparts of the other system [2-12]. Besides the classical synchronization of two chaotic systems, antisynchronization can also be generated by two chaotic systems, which means the variables of one system achieve the consensus with the negative values of counterparts of the other system [13-15]. It should be pointed out that the mixed synchronization (coexistence of synchronization and antisynchronization) has been observed for some chaotic systems, which means that some variables of one chaotic system achieve synchronization with the counterpart variables of the other chaotic system, and the other variables of chaotic systems achieve antisynchronization simultaneously [16-18].

The synchronization of two chaotic financial systems has been widely investigated in [19-25]. However, to the best of author's knowledge, there are limited studies to investigate the coexistence of synchronization and antisynchronization of two chaotic financial systems [26,27], in which the nonlinear control method (adaptive control) was used to achieve mixed synchronization. Within those existing studies of synchronization (not mixed synchronization) of two chaotic financial systems, the nonlinear control methods (active control and adaptive control) were utilized in [19-25]. Therefore, we focus on using the linear feedback control to achieve the coexistence of synchronization and antisynchronization of two chaotic financial systems.

In this paper, the mixed synchronization of two chaotic financial systems is studied. Two mixed synchronization criteria are derived with a single controller and without external controls for mixed synchronization of two chaotic financial systems, respectively. Those synchronization criteria and the control method are applied to investigate the mixed synchronization of a class of modified chaotic financial systems. 
The effectiveness of our results is demonstrated by three simulation examples.

\section{Preliminaries}

Consider the following chaotic financial system:

$$
\begin{aligned}
& \frac{d x_{1}(t)}{d t}=x_{3}(t)+\left(x_{2}(t)-a\right) x_{1}(t), \\
& \frac{d x_{2}(t)}{d t}=1-b x_{2}(t)-x_{1}^{2}(t), \\
& \frac{d x_{3}(t)}{d t}=-x_{1}(t)-c x_{3}(t),
\end{aligned}
$$

where $x_{1}(t), x_{2}(t)$, and $x_{3}(t)$ are the interest rate, the investment demand, and the price index, respectively. Constants $a$, $b$, and $c$ are parameters which represent the saving amount, the cost per investment, and the elasticity of demand of commercial markets, receptively. $x_{1}(0)=x_{1_{0}}, x_{2}(0)=x_{2_{0}}$, and $x_{3}(0)=x_{3_{0}}$ are the initial conditions of (1).

System (1) can be regarded as a master system. One can construct the following slave system:

$$
\begin{aligned}
\frac{d y_{1}(t)}{d t}= & y_{3}(t)+\left(y_{2}(t)-a\right) y_{1}(t) \\
& -k_{1}\left(x_{1}(t)+y_{1}(t)\right), \\
\frac{d y_{2}(t)}{d t}= & 1-b y_{2}(t)-y_{1}^{2}(t)+k_{2}\left(x_{2}(t)-y_{2}(t)\right), \\
\frac{d y_{3}(t)}{d t}= & -y_{1}(t)-c y_{3}(t)-k_{3}\left(x_{3}(t)+y_{3}(t)\right),
\end{aligned}
$$

where $y_{1}(t), y_{2}(t)$, and $y_{3}(t)$ represent the state variables and $k_{1}, k_{2}$, and $k_{3}$ are gains. The initial conditions of (2) are given by $y_{1}(0)=y_{1_{0}}, y_{2}(0)=y_{2_{0}} \cdot y_{3}(0)=y_{3_{0}}$.

The definition of synchronization of chaotic systems (1) and (2) refers to

$$
\lim _{t \rightarrow \infty}\left(x_{i}(t)-y_{i}(t)\right)=0, \quad \text { for } i=1,2,3 .
$$

The antisynchronization of chaotic systems (1) and (2) is given as

$$
\lim _{t \rightarrow \infty}\left(x_{i}(t)+y_{i}(t)\right)=0, \quad \text { for } i=1,2,3 \text {. }
$$

In this paper, the coexistence of antisynchronization and synchronization of chaotic systems (1) and (2) will be investigated; that is, some variables of chaotic systems (1) and (2) achieve antisynchronization, and the other variables of chaotic systems (1) and (2) achieve synchronization, which can be noted as the mixed synchronization of chaotic systems (1) and (2). In this paper, we focus on the case

$$
\begin{aligned}
& \lim _{t \rightarrow \infty}\left(x_{1}(t)+y_{1}(t)\right)=0, \\
& \lim _{t \rightarrow \infty}\left(x_{2}(t)-y_{2}(t)\right)=0, \\
& \lim _{t \rightarrow \infty}\left(x_{3}(t)+y_{3}(t)\right)=0 .
\end{aligned}
$$

Let $E_{1}(t)=x_{1}(t)+y_{1}(t), e_{2}(t)=x_{2}(t)-y_{2}(t)$, and $E_{3}(t)=$ $x_{3}(t)+y_{3}(t)$. Thus, one can derive the following error system:

$$
\begin{aligned}
\frac{d E_{1}(t)}{d t}= & -\left(a+k_{1}\right) E_{1}(t)+E_{3}(t)+E_{1}(t) x_{2}(t) \\
& -y_{1}(t) e_{2}(t), \\
\frac{d e_{2}(t)}{d t}= & -\left(b+k_{2}\right) e_{2}(t)-E_{1}(t)\left(x_{1}(t)-y_{1}(t)\right), \\
\frac{d E_{3}(t)}{d t}= & -E_{1}(t)-\left(c+k_{3}\right) E_{3}(t) .
\end{aligned}
$$

The initial conditions of $(6)$ are $E_{1}(0)=x_{1_{0}}+y_{1_{0}}, e_{2}(0)=$ $x_{2_{0}}-y_{2_{0}}$, and $E_{3}(0)=x_{3_{0}}+y_{3_{0}}$.

\section{Main Results}

In this section, some mixed synchronization criteria for chaotic financial systems will be given.

One can define the following Lyapunov function:

$$
V(t)=\frac{E_{1}^{2}(t)+e_{2}^{2}(t)+E_{3}^{2}(t)}{2} .
$$

Theorem 1. If the following inequalities hold:

$$
\begin{aligned}
& \max \left\{x_{2}(t), \forall t \geq 0\right\}<a+k_{1}, \\
& 0<b+k_{2}, \\
& 0<c+k_{3}, \\
& \max \left\{\left|x_{1}^{2}(t)\right|, \forall t \geq 0\right\} \\
& \quad<4\left(a+k_{1}-\max \left\{x_{2}(t), \forall t \geq 0\right\}\right)\left(b+k_{2}\right),
\end{aligned}
$$

then two chaotic financial systems described by (1) and (2) can achieve global mixed synchronization.

Proof. Calculating the derivative of $V(t)$ along with (6) yields

$$
\begin{aligned}
\frac{d V(t)}{d t}= & -\left(a+k_{1}\right) E_{1}^{2}(t)+E_{1}(t) E_{3}(t) \\
& +E_{1}^{2}(t) x_{2}(t)-E_{1}(t) e_{2}(t) y_{1}(t) \\
& -\left(b+k_{2}\right) e_{2}^{2}(t)-e_{2} E_{1}(t)\left(x_{1}(t)-y_{1}(t)\right) \\
& -E_{1}(t) E_{3}(t)-\left(c+k_{3}\right) E_{3}^{2}(t) \\
= & -\left(a+k_{1}-x_{2}(t)\right) E_{1}^{2}(t)-\left(b+k_{2}\right) e_{2}^{2}(t) \\
& -x_{1}(t) E_{1}(t) e_{2}(t)-\left(c+k_{3}\right) E_{3}^{2}(t) .
\end{aligned}
$$

Condition (11) gives

$$
x_{1}^{2}(t)<4\left(a+k_{1}-x_{2}(t)\right)\left(b+k_{2}\right) .
$$


Inequalities $\max \left\{x_{2}(t), \forall t \geq 0\right\}<a+k_{1}, 0<b+k_{2}$ in (8)-(9) and the inequality described by (13) indicate

$$
\begin{gathered}
-\left(a+k_{1}-x_{2}(t)\right) E_{1}^{2}(t)-\left(b+k_{2}\right) e_{2}^{2}(t) \\
-x_{1}(t) E_{1}(t) e_{2}(t)<0, \quad \forall t \geq 0 .
\end{gathered}
$$

The inequality described by (14) and $c+k_{3}>0$ in (10) imply that

$$
\frac{d V(t)}{d t}<0, \quad \forall E_{1}(t), e_{2}(t), E_{3}(t) \neq 0 .
$$

Using LaSalle invariant principle derives that the trajectories of (6) will be convergent to the largest invariant set in $d V(t) / d t=0$ when $t \rightarrow \infty$. This ends the proof.

Remark 2. Theorem 1 gives a mixed synchronization criterion for chaotic financial systems (1) and (2). Compared with existing synchronization results in $[19-23,25]$ for chaotic financial systems by using nonlinear feedback controls (the active control and adaptive control), the linear feedback control is used in Theorem 1.

Remark 3. In [19-23], hyperchaotic financial systems with four dimensions were studied. This paper mainly investigates the mix synchronization of three-dimensional chaotic financial systems (1). How to achieve mix synchronization of four-dimensional hyperchaotic financial systems by using the linear feedback control is our research work in the future.

If $c>0$ and $k_{3}=0$, one can have the following corollary.

Corollary 4. If $c>0, k_{3}=0$, and the following inequalities hold:

$$
\begin{aligned}
& \max \left\{x_{2}(t), \forall t \geq 0\right\}<a+k_{1}, \\
& 0<b+k_{2}, \\
& \max \left\{\left|x_{1}^{2}(t)\right|, \forall t \geq 0\right\} \\
& \quad<4\left(a+k_{1}-\max \left\{x_{2}(t), \forall t \geq 0\right\}\right)\left(b+k_{2}\right),
\end{aligned}
$$

then two chaotic financial systems described by (1) and (2) can achieve global mixed synchronization.

If $c>0, b>0$, and $k_{2}=k_{3}=0$, one can have the following theorem.

Theorem 5. If $c>0, b>0, k_{2}=k_{3}=0$, and the following inequalities hold:

$$
\begin{aligned}
& \max \left\{x_{2}(t), \forall t \geq 0\right\}<a+k_{1}, \\
& \max \left\{\left|x_{1}^{2}(t)\right|, \forall t \geq 0\right\} \\
& \quad<4\left(a+k_{1}-\max \left\{x_{2}(t), \forall t \geq 0\right\}\right) b,
\end{aligned}
$$

then two chaotic financial systems described by (1) and (2) can achieve global mixed synchronization.

Remark 6. Theorem 5 gives a mixed synchronization criterion, in which only a single controller $k_{1} E_{1}(t)$ is used.
Remark 7. In [26], the control $u(t)=k(t)\left(x_{1}(t)+y_{1}(t)\right)$ was added to the slave financial system

$$
\begin{aligned}
\frac{d y_{1}(t)}{d t}= & y_{3}(t)+\left(y_{2}(t)-a\right) y_{1}(t) \\
& +k(t)\left(x_{1}(t)+y_{1}(t)\right) \\
\frac{d y_{2}(t)}{d t}= & 1-b y_{2}(t)-y_{1}^{2}(t) \\
\frac{d y_{3}(t)}{d t}= & -y_{1}(t)-c y_{3}(t)
\end{aligned}
$$

where

$$
\frac{d k(t)}{d t}=-r\left(x_{1}(t)+y_{1}(t)\right)^{2} .
$$

In addition, a Lyapunov function was given as follows:

$$
\widetilde{V}(t)=\frac{E_{1}^{2}(t)+e_{2}^{2}(t)+E_{3}^{2}(t)}{2}+\frac{\left(k(t)+L_{3}\right)^{2}}{2 r},
$$

where $E_{1}(t), e_{2}(t)$, and $E_{3}(t)$ are the same as those defined in (6). By using adaptive control technique and calculating the derivatives of $\widetilde{V}(t)$, two chaotic financial systems described by (1) and (18) can achieve mixed synchronization under the conditions such that

$$
L_{3}>M_{3} \sup _{E_{1}(t) \neq 0} \frac{e_{2}(t)^{2}+E_{1}(t)^{2}+E_{3}(t)^{2}}{E_{1}(t)^{2}},
$$

where $M_{3}=\max _{i=1}^{3} n_{i}$ and $n_{1}, n_{2}$, and $n_{3}$ were constants such that

$$
\begin{aligned}
& E_{1}(t)\left(-a E_{1}(t)+E_{3}(t)+E_{1}(t) x_{2}(t)-y_{1}(t) e_{2}(t)\right) \\
& \quad \leq n_{1} E_{1}(t)^{2}, \\
& e_{2}(t)\left(-b e_{2}(t)-E_{1}(t)\left(x_{1}(t)-y_{1}(t)\right)\right) \leq n_{2} e_{2}(t)^{2}, \\
& E_{3}(t)\left(-E_{1}(t)-c E_{3}(t)\right) \leq n_{3} E_{3}(t)^{2} .
\end{aligned}
$$

It should be pointed out that it is difficult to obtain $n_{1}, n_{2}$, $n_{3}$, and $L_{3}$ which increases the complexity of using mixed synchronization in [26]. The similar method was used to achieve mixed synchronization for two four-dimensional hyperchaotic financial systems in [27].

Remark 8. Compared with the difficulty to access $n_{1}, n_{2}$, $n_{3}$, and $L_{3}$ in mixed synchronization results of $[26,27]$, Theorem 5 is easier to be used.

If $a>0, b>0, c>0$, and $k_{1}=k_{2}=k_{3}=0$, one can have the following theorem.

Theorem 9. If $c>0, b>0, c>0, k_{1}=k_{2}=k_{3}=0$, and the following inequalities hold:

$$
\begin{aligned}
\max & \left\{x_{2}(t), \forall t \geq 0\right\}<a, \\
\max & \left\{\left|x_{1}^{2}(t)\right|, \forall t \geq 0\right\} \\
& <4\left(a-\max \left\{x_{2}(t), \forall t \geq 0\right\}\right) b,
\end{aligned}
$$


then two financial systems described by (1) and (2) can achieve global mixed synchronization.

Remark 10. If parameters $a, b$, and $c$ satisfy inequalities (23), two financial systems described by (1) and (2) can achieve global mixed synchronization without external controls.

\section{An Application to Mixed Synchronization of Modified Chaotic Financial Systems}

If $a=\widehat{a}-d$, the chaotic financial system described by (1) can be transformed to the following system:

$$
\begin{aligned}
& \frac{d x_{1}(t)}{d t}=x_{3}(t)+\left(x_{2}(t)-\widehat{a}\right) x_{1}(t)+d x_{1}(t) \\
& \frac{d x_{2}(t)}{d t}=1-b x_{2}(t)-x_{1}^{2}(t) \\
& \frac{d x_{3}(t)}{d t}=-x_{1}(t)-c x_{3}(t)
\end{aligned}
$$

where $d$ is a constant and $x_{1}(t), x_{2}(t), x_{3}(t), a, b$, and $c$ are the same as those defined in (1). The initial conditions of (24) are the same as those in (1). System (24) was noted as the modified chaotic financial system in [24].

It should be pointed out that Theorems 1, 5, and 9 and Corollary 4 are still valid for the mixed synchronization of modified chaotic financial systems described by (24) with $a=\widehat{a}-d$.

Remark 11. In [24], a nonlinear control method was used to achieve synchronization for modified chaotic financial systems described by (24). However, our mixed synchronization criteria (Theorems 1 and 5 and Corollary 4 ) are derived by the linear feedback control.

\section{Three Illustrated Examples}

Example 1. Consider chaotic financial systems (1) and (2) with $a=0.9, b=0.2$, and $c=1.5$. The initial conditions of (1) and (2) are $x_{1_{0}}=1, x_{2_{0}}=1, x_{3_{0}}=1, y_{1_{0}}=1.1, y_{2_{0}}=1.2$, and $y_{3_{0}}=1.1$, respectively. Figure 1 illustrates the chaotic attractor of chaotic system (1). From Figure 1, one can see that $-2.4 \leq x_{1}(t) \leq 2.4$ and $-0.3 \leq x_{2}(t) \leq 3.2$ for $t \geq 0$.

Due to $c=1.5>0, b=0.2>0$, and $\max \left\{\left|x_{1}^{2}(t)\right|, \forall t \geq\right.$ $0\}=2.4^{2}<4\left(a-\max \left\{x_{2}(t), \forall t \geq 0\right\}\right) b=4\left(0.9+k_{1}-3.2\right) 0.2$, one can use Theorem 5 to derive that $k_{1}>9.5$ and $k_{2}=$ $k_{3}=0$. Let $k_{1}=9.6$. Figures 2 and 3 demonstrate the trajectories of systems (1) and (2), respectively. Figures 4, 5, and 6 illustrate trajectories $E_{1}(t), e_{2}(t)$, and $E_{3}(t)$ of system (6), respectively, which clearly show that (1) and (2) achieve mixed synchronization. The unit of time $t$ in Figures 4,5 , and 6 is the second.

Example 2. Consider two financial systems (1) and (2) with $a=3.9, b=0.5$, and $c=1.5$ and $x_{1_{0}}=1, x_{2_{0}}=-0.2, x_{3_{0}}=1$, $y_{1_{0}}=1.1, y_{2_{0}}=1.2$, and $y_{3_{0}}=1.1$. The bounds of $x_{1}(t)$ and $x_{2}(t)$ are $-0.1 \leq x_{1}(t) \leq 1$ and $-0.2 \leq x_{2}(t) \leq 2$ for $t \geq 0$.

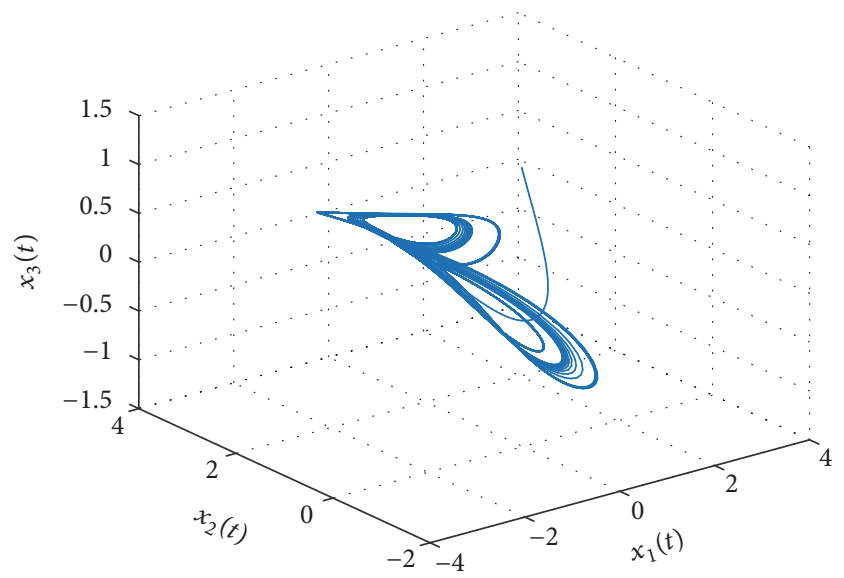

Figure 1: Chaotic attractor of system (1) with $a=0.9, b=0.2$, and $c=1.5$.

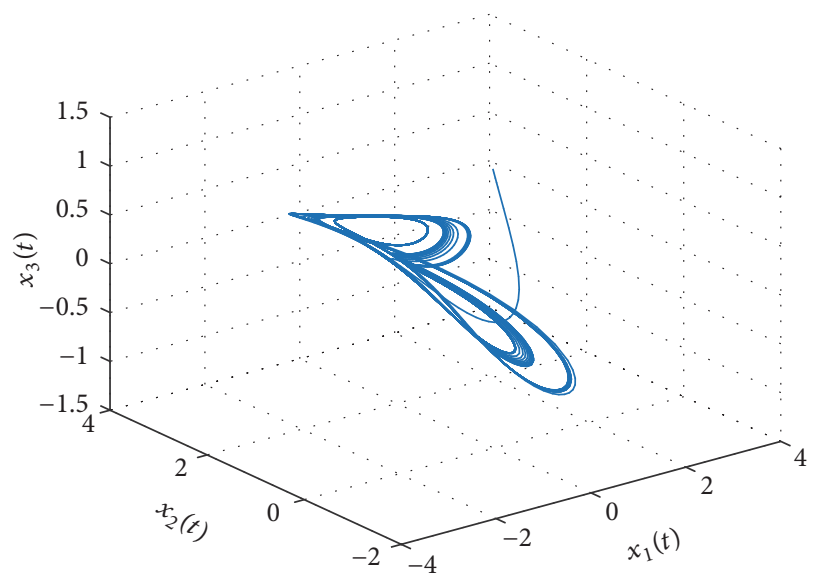

FIGURE 2: Phase figure of system (1) with $a=0.9, b=0.2$, and $c=$ 1.5 .

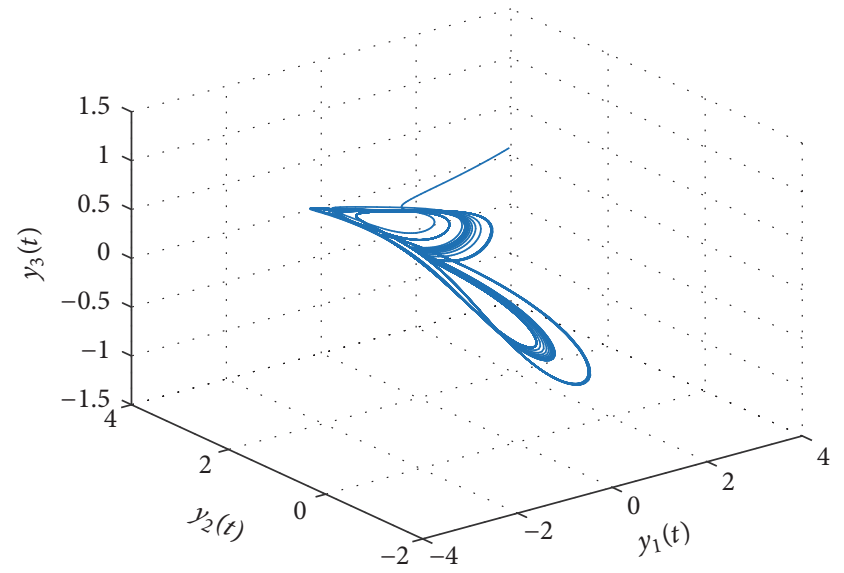

FIGURE 3: Phase figure of system (2) with $a=0.9, b=0.2, c=1.5$, $k_{1}=9.6$, and $k_{2}=k_{3}=0$.

Due to $a=3.9>0, c=1.5>0, b=0.5>0$, and $\max \left\{\left|x_{1}^{2}(t)\right|, \forall t \geq 0\right\}=1<4\left(a-\max \left\{x_{2}(t), \forall t \geq 0\right\}\right) b=3.8$, one can use Theorem 9 to derive that $k_{1}=k_{2}=k_{3}=0$. 


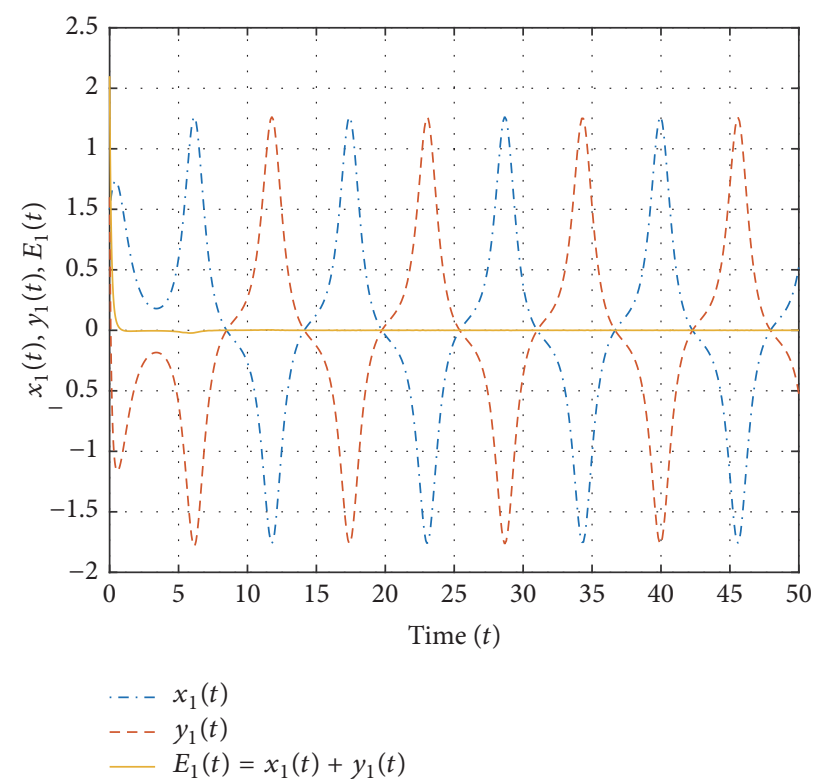

Figure 4: Trajectories $x_{1}(t)$ and $y_{1}(t)$ of system (1) and system (2) and $E_{1}(t)$ of system (6) with $a=0.9, b=0.2, c=1.5, k_{1}=9.6$, and $k_{2}=k_{3}=0$.

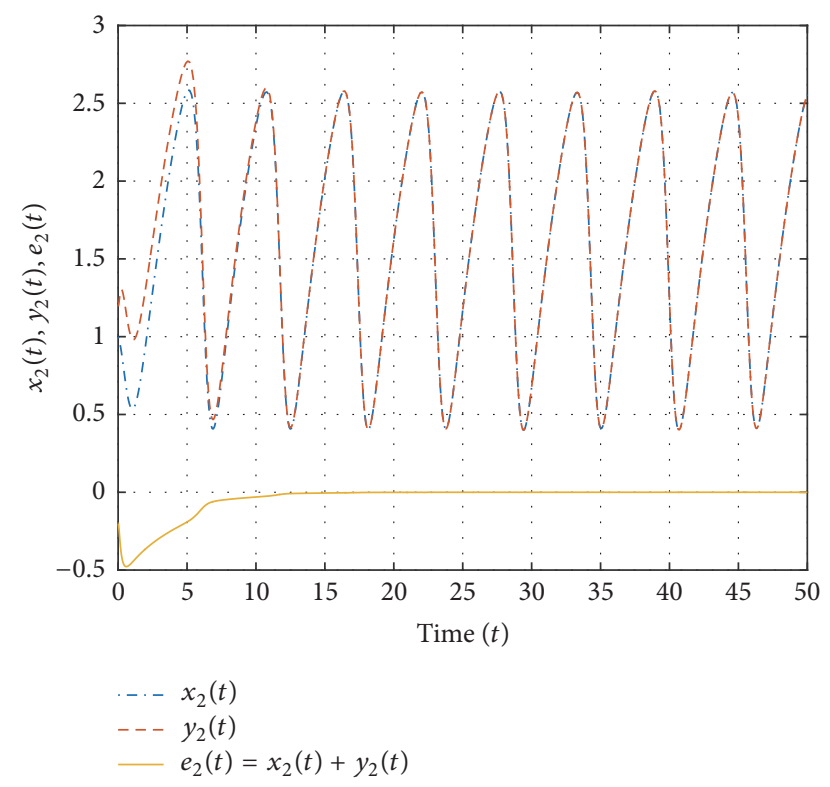

FIGURE 5: Trajectories $x_{2}(t)$ and $y_{2}(t)$ of system (1) and system (2) and $e_{2}(t)$ of system (6) with $a=0.9, b=0.2, c=1.5, k_{1}=9.6$, and $k_{2}=k_{3}=0$.

Figure 7 demonstrates the trajectories of (6), which clearly illustrates that systems (1) and (2) achieve mixed synchronization. The unit of time $t$ in Figure 7 is the second.

Example 3. Consider the modified financial system described by (24) with $\widehat{a}=0.6, b=0.2, c=0.9$, and $d=0.5$ which can be transformed to (1) with $a=0.1, b=0.2$, and $c=0.9$. Consider (1) and (2) with $a=0.1, b=0.2$, and $c=0.9$ and $x_{1_{0}}=1, x_{2_{0}}=1, x_{3_{0}}=1, y_{1_{0}}=1.1, y_{2_{0}}=1.2$, and $y_{3_{0}}=1.1$.

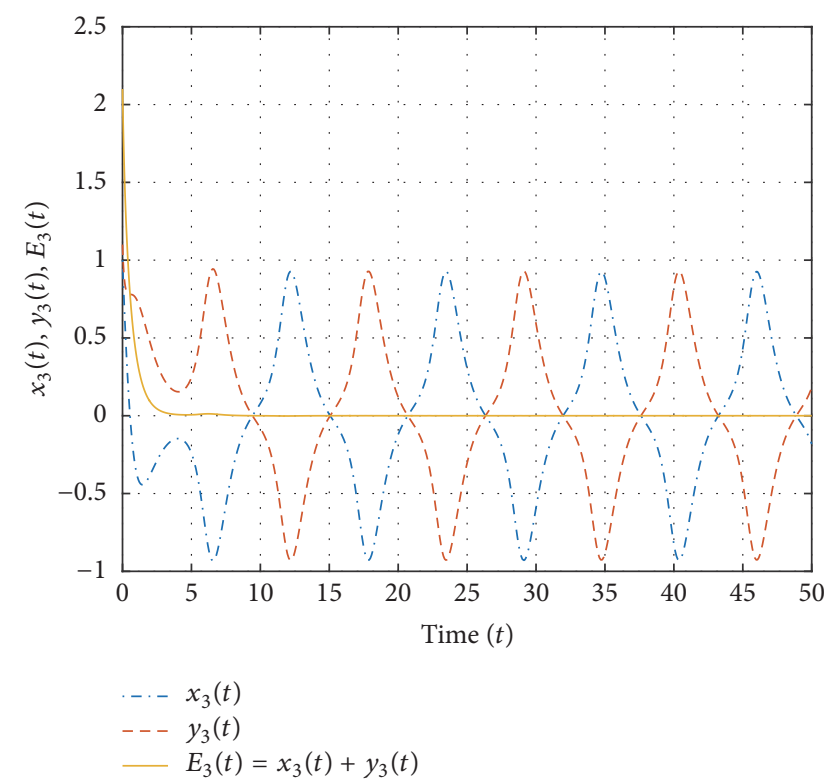

Figure 6: Trajectories $x_{3}(t)$ and $y_{3}(t)$ of system (1) and system (2) and $E_{3}(t)$ of system (6) with $a=0.9, b=0.2, c=1.5, k_{1}=9.6$, and $k_{2}=k_{3}=0$.

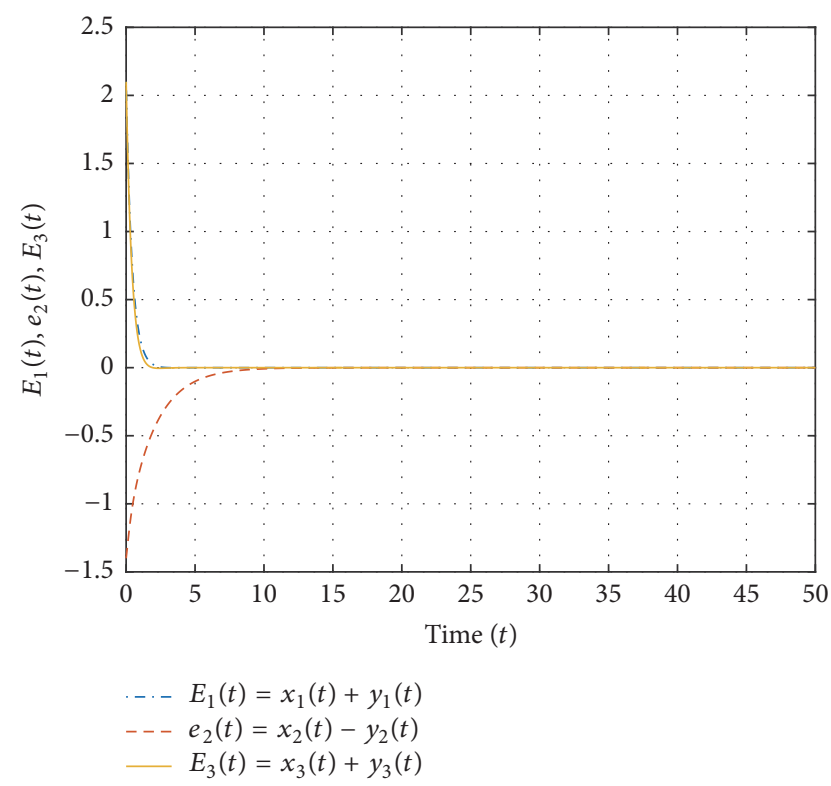

Figure 7: Trajectories of $E_{1}(t), e_{2}(t)$, and $E_{3}(t)$ of system (6) with $a=3.9, b=0.5, c=1.5$, and $k_{1}=k_{2}=k_{3}=0$.

The bounds of $x_{1}(t)$ and $x_{2}(t)$ are $-3 \leq x_{1}(t) \leq 3$ and $-1.7 \leq$ $x_{2}(t) \leq 3.1$ for $t \geq 0$.

Due to $a=\widehat{a}-d=0.1>0, c=0.9>0, b=$ $0.2>0$, and $\max \left\{\left|x_{1}^{2}(t)\right|, \forall t \geq 0\right\}=3^{2}<4\left(\widehat{a}-d+k_{1}-\right.$ $\left.\max \left\{x_{2}(t), \forall t \geq 0\right\}\right) b$, one can use Theorem 5 to derive that $k_{1}>14.25$ and $k_{2}=k_{3}=0$. One can choose $k_{1}=14.26$ and $k_{2}=k_{3}=0$. Figure 8 demonstrates the trajectories of (6), which clearly shows that systems (1) and (2) achieve mixed synchronization. The unit of time $t$ in Figure 8 is the second. 


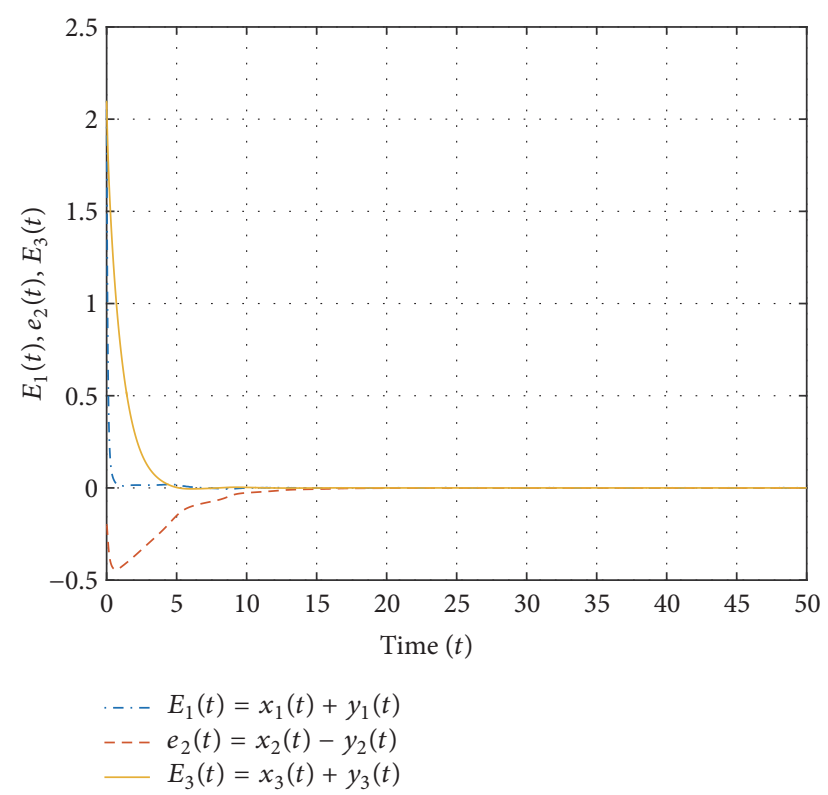

FIGURE 8: Trajectories of $E_{1}(t), e_{2}(t)$, and $E_{3}(t)$ of system (6) with $a=0.1, b=0.2, c=0.9, \hat{a}=0.6, d=0.5, k_{1}=14.26$, and $k_{2}=k_{3}=$ 0 .

\section{Conclusions and Future Works}

We have derived some mixed synchronization criteria for chaotic financial systems, in which the synchronization and antisynchronization coexist in chaotic financial systems by using linear feedback control, rather than nonlinear controls in the previous results. Moreover, we have obtained two mixed synchronization criteria with a single controller and without external controls, respectively. In addition, we have applied the mixed synchronization criteria and the control method to study the mixed synchronization for a class of modified chaotic financial systems. We have used three examples to illustrate the effectiveness of our derived results. In this paper, the synchronization and antisynchronization coexist in two identical financial systems with three dimensions. How to achieve the coexistence of synchronization and antisynchronization in two four-dimensional financial systems with mismatched parameters by using linear feedback control or nonlinear control is our research interest in the future.

\section{Competing Interests}

The authors declare that they have no competing interests.

\section{Acknowledgments}

This paper is partially supported by the National Natural Science Foundation of China under Grant 61561023, the Key Project of Youth Science Fund of Jiangxi China under Grant 20133ACB21009, the project of CSC Jiangxi, and the project of Jiangxi E-Commerce High Level Engineering Technology Research Centre.

\section{References}

[1] J. H. Ma and Y. S. Chen, "Study for the bifurcation topological structure and the global complicated character of a kind of nonlinear finance system," Applied Mathematics and Mechanics, vol. 22, no. 11, pp. 1119-1128, 2001.

[2] L. M. Pecora and T. L. Carroll, "Synchronization of chaotic systems," Chaos, vol. 25, no. 9, Article ID 097611, 12 pages, 2015.

[3] K. Ding and X. Xu, "Chaotic synchronization of modified discrete-time tinkerbell systems," Discrete Dynamics in Nature and Society, vol. 2016, Article ID 5218080, 7 pages, 2016.

[4] K. Ding and Q. Han, "Master-slave synchronization criteria for chaotic hindmarsh-rose neurons using linear feedback control," Complexity, vol. 21, no. 5, pp. 319-327, 2016.

[5] K. Ding and Q.-L. Han, "Synchronization of two coupled Hindmarsh-Rose neurons," Kybernetika, vol. 51, no. 5, pp. 784-799, 2015.

[6] D. Arroyo and G. Alvarez, "Application of Gray codes to the study of the theory of symbolic dynamics of unimodal maps," Communications in Nonlinear Science and Numerical Simulation, vol. 19, no. 7, pp. 2345-2353, 2014.

[7] D. Arroyo, J. Diaz, and F. B. Rodriguez, "Cryptanalysis of a one round chaos-based Substitution Permutation Network," Signal Processing, vol. 93, no. 5, pp. 1358-1364, 2013.

[8] D. Arroyo, G. Alvarez, J. Amigó, and S. Li, "Cryptanalysis of a family of self-synchronizing chaotic stream ciphers," Communications in Nonlinear Science and Numerical Simulation, vol. 16, no. 2, pp. 805-813, 2011.

[9] T. Lu and G. Chen, "Proximal and syndetical properties in nonautonomous discrete systems," Journal of Applied Analysis and Computation, vol. 7, no. 1, pp. 92-101, 2017.

[10] M. A. Khan and B. Sahoo, "Temporospatial synchronization of discrete Logistic map through complex network," Optik, vol. 127, no. 3, pp. 1526-1531, 2016.

[11] W.-H. Chen, X. Lu, and W. X. Zheng, "Impulsive stabilization and impulsive synchronization of discrete-time delayed neural networks," IEEE Transactions on Neural Networks and Learning Systems, vol. 26, no. 4, pp. 734-748, 2015.

[12] Y. Liu, Z. Wang, J. Liang, and X. Liu, "Stability and synchronization of discrete-time Markovian jumping neural networks with mixed mode-dependent time delays," IEEE Transactions on Neural Networks, vol. 20, no. 7, pp. 1102-1116, 2009.

[13] M. M. El-Dessoky, "Anti-synchronization of four scroll attractor with fully unknown parameters," Nonlinear Analysis: Real World Applications, vol. 11, no. 2, pp. 778-783, 2010.

[14] M. Mossa Al-Sawalha and M. S. M. Noorani, "Anti-synchronization of two hyperchaotic systems via nonlinear control," Communications in Nonlinear Science and Numerical Simulation, vol. 14, no. 8, pp. 3402-3411, 2009.

[15] M. M. Al-sawalha, M. S. Noorani, and M. Al-dlalah, "Adaptive anti-synchronization of chaotic systems with fully unknown parameters," Computers \& Mathematics with Applications, vol. 59, no. 10, pp. 3234-3244, 2010.

[16] S. K. Bhowmick, C. Hens, D. Ghosh, and S. K. Dana, "Mixed synchronization in chaotic oscillators using scalar coupling," Physics Letters A, vol. 376, no. 36, pp. 2490-2495, 2012.

[17] J.-H. Chen, H.-K. Chen, and Y.-K. Lin, "Synchronization and anti-synchronization coexist in Chen-Lee chaotic systems," Chaos, Solitons and Fractals, vol. 39, no. 2, pp. 707-716, 2009.

[18] H.-T. Yau, "Synchronization and anti-synchronization coexist in two-degree-of-freedom dissipative gyroscope with nonlinear 
inputs," Nonlinear Analysis: Real World Applications, vol. 9, no. 5, pp. 2253-2261, 2008.

[19] J. A. Vargas, E. Grzeidak, and E. M. Hemerly, "Robust adaptive synchronization of a hyperchaotic finance system," Nonlinear Dynamics, vol. 80, no. 1-2, pp. 239-248, 2015.

[20] C. R. Xie, Y. H. Xu, and D. B. Tong, "Chaos synchronization of financial chaotic system with external perturbation," Discrete Dynamics in Nature and Society, vol. 2015, Article ID 731376, 7 pages, 2015.

[21] J. Zheng and B. Du, "Projective synchronization of hyperchaotic financial systems," Discrete Dynamics in Nature and Society, vol. 2015, Article ID 782630, 9 pages, 2015.

[22] G. Cai, P. Hu, and Y. Li, "Modified function lag projective synchronization of a financial hyperchaotic system," Nonlinear Dynamics, vol. 69, no. 3, pp. 1457-1464, 2012.

[23] X. Chai, Z. Gan, and C. Shi, "Impulsive synchronization and adaptive-impulsive synchronization of a novel financial hyperchaotic system," Mathematical Problems in Engineering, vol. 2013, Article ID 751616, 10 pages, 2013.

[24] M. Z. Yang, B. Cai, and G. L. Cai, "Projective synchronization of a modified three-dimensional chaotic finance system," International Journal of Nonlinear Science, vol. 10, no. 1, pp. 32-38, 2010.

[25] Y. H. Xu, C. R. Xie, Y. L. Wang, W. Zhou, and J. A. Fang, "Chaos projective synchronization of the chaotic finance system with parameter switching perturbation and input time-varying delay," Mathematical Methods in the Applied Sciences, vol. 38, no. 17, pp. 4279-4288, 2015.

[26] R. W. Guo, L. Bin, and Z. G. Yan, "Serval control problems of a novel finance chaotic system," in Proceedings of the 27th Chinese Control and Decision Conference (CCDC '15), pp. 3844-3849, Qingdao, China, May 2015.

[27] L. Liu, L. Ren, X. Bei, R. Guo, Z. Yan, and P. Zhao, "Coexistence of synchronization and anti-synchronization in the unified chaotic systems," in Proceedings of the 34th Chinese Control Conference (CCC '15), pp. 8590-8594, Hangzhou, China, July 2015. 


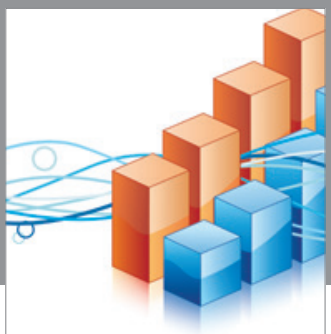

Advances in

Operations Research

vatem alat4

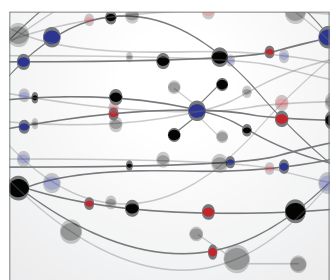

\section{The Scientific} World Journal
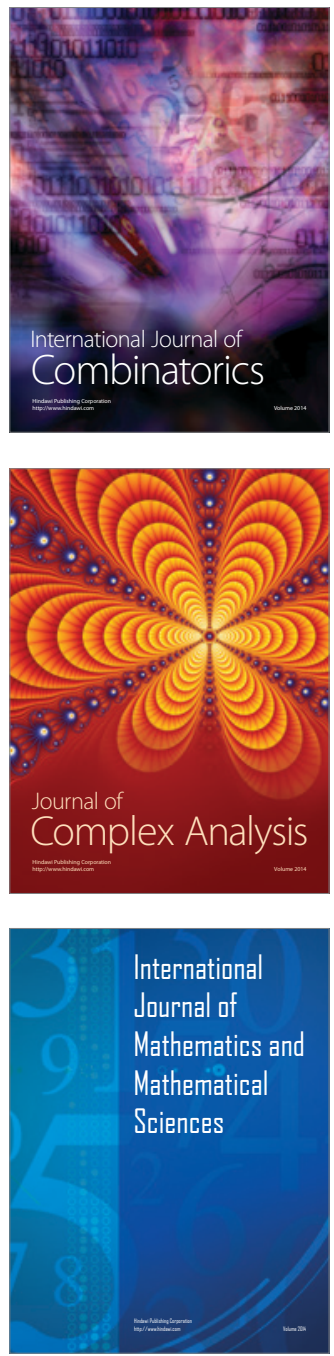
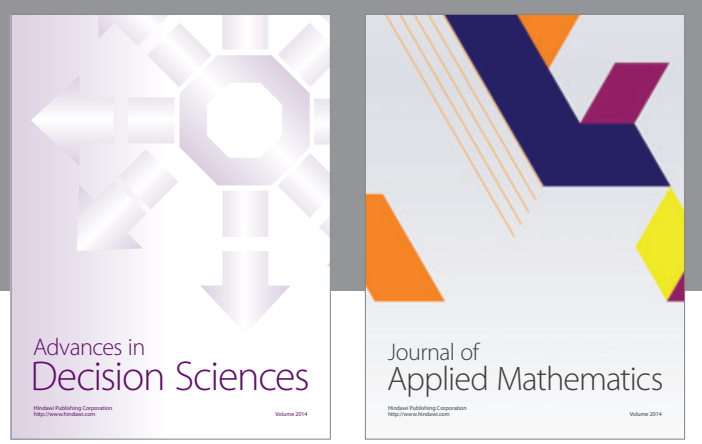

Algebra

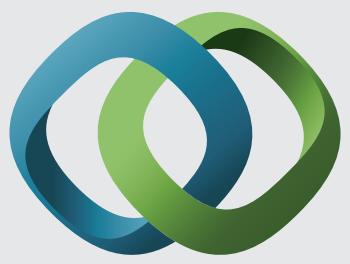

\section{Hindawi}

Submit your manuscripts at

http://www.hindawi.com
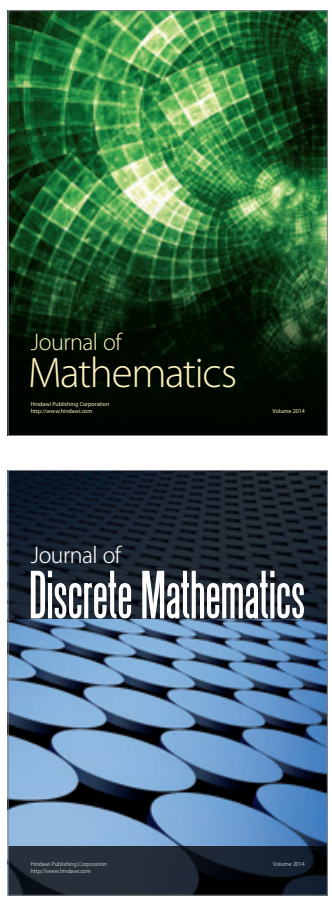

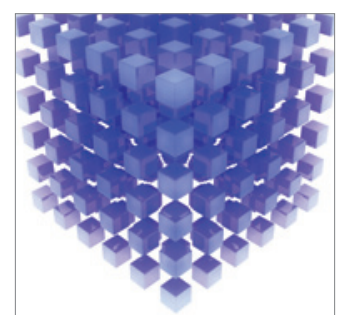

Mathematical Problems in Engineering
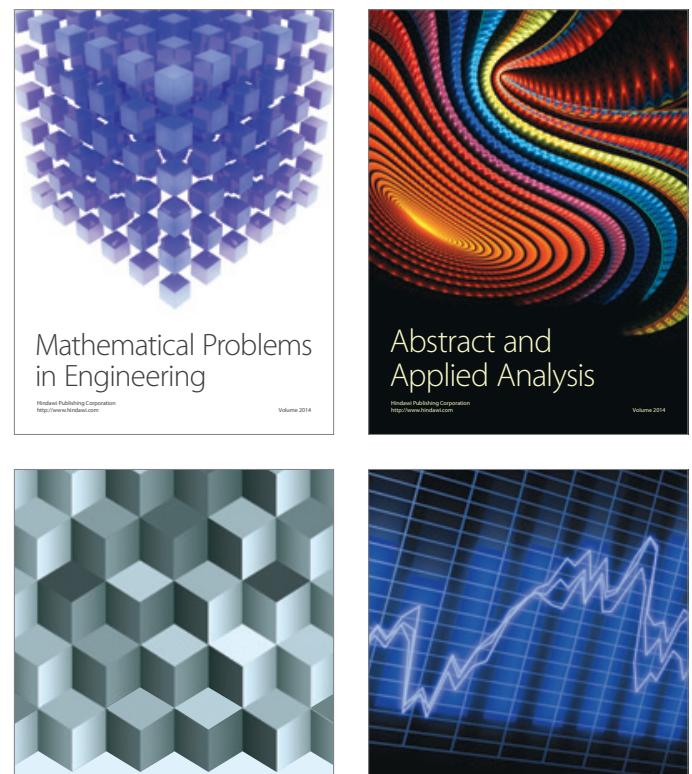

Journal of

Function Spaces

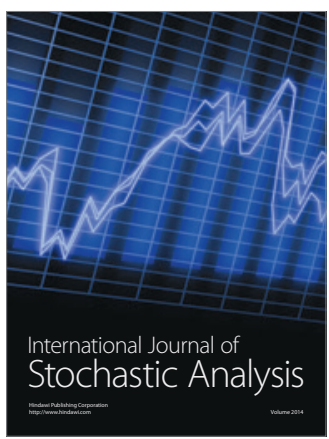

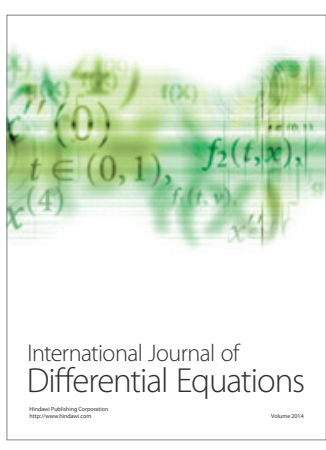
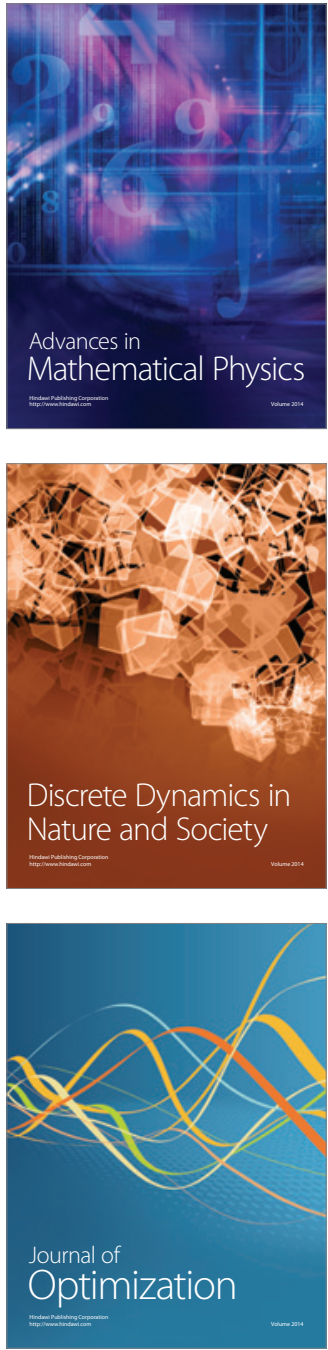